\title{
Da Arte de se Traduzir: corporalidades e gênero nos mundos possíveis no ciberespaço ${ }^{1}$
}

Jean Segata

(PPGAS/UFSC)
Uma parte de mim

é todo mundo:

outra parte é ninguém:

fundo sem fundo.

[...]

Uma parte de mim

é permanente:

outra parte

se sabe de repente.

[...]

Traduzir uma parte

na outra parte

- que é uma questão

de vida ou morte -

será arte?

"Traduzir-se"

Ferreira Gullar

DE TARDE, UMA (E OUTRA) INSPIRAÇÃO

Afinal, quem são estes que me transformam? Em que parte de mim sou eu mesmo, se é que sou em alguma parte? E se em algum lugar eu sou, que arte é essa de traduzir uma parte de mim na outra parte? Em que parte de mim estão todos os outros e quem eles são? Quando Gabriel Tarde, ainda no século XIX, sugeria a noção infinitesimal de que aquilo que hoje tratamos por sociedade seria uma possessão recíproca de associações entre todos, tudo e por cada um, considerando a diferença uma relação e a relação uma diferença, a história das Ciências Sociais 
coesos e previsíveis. A diferença infinitesimal se perdeu, salvo parcamente reconstruída nos discursos sócioantropológicos mais contemporâneos.

A saber, Gabriel Tarde é tido como um dos mais notáveis sociólogos da França dos fins do século XIX. Sua participação na constituição e na emergência da sociologia nesse país é inquestionável, estando o seu ostracismo na história do pensamento sociológico diametralmente associado à centralidade que a sociologia durkheiminiana foi ganhando na época (Vargas 1995, 2000). Com os recentes debates na antropologia, que têm posto à prova a validade analítica dos grandes e polivalentes conceitos que edificaram a disciplina desde o século XVIII, tais quais sociedade, indivíduo, natureza, cultura, fundados em parte sobre os princípios durkheiminianos da unidade, e combinados como pares opositores com a ascensão do estruturalismo, na metade do século XX, o resgate da obra de Gabriel Tarde faz-se oportuno, uma vez que, entre outras coisas, na sociologia da diferença desse autor, “o que conta não são os indivíduos, mas as relações infinitesimais de repetição, oposição e adaptação que se desenvolvem entre ou nos indivíduos, ou melhor, num plano onde não faz sentido algum distinguir o social e o individual" (Vargas 2007:10). Sua ruptura com a sociologia de Durkheim traça uma direção contrária nas Ciências Sociais: ao invés de se preocupar com as unidades que compõem instâncias ontológicas auto-perpetuáveis, Tarde, inspirado na monadologia de Leibniz, preocupa-se com a diferença e com a infinitesimal possibilidade de variabilidade dos sujeitos, propondo substituir "o grande pelo pequeno, as totalidades e as unidades pelas multidões" (ibid.:15).

Para tanto, a atitude radical de inspiração tardeana sugere que se admita que "há infinitamente mais agentes no mundo do que correntemente imaginam nossas ciências humanas" (ibid.:13). Em parte, para citar um exemplo, é esta a sugestão fundadora de etnografias contemporâneas, especialmente aquelas sobre os povos das Terras Altas e Baixas do Amazonas, ao demarcarem a centralidade que a agência de outras entidades, tais os animais, os fenômenos da natureza ou os espíritos têm na composição das relações sociais desses povos. Neste caso, é preciso estar atento para o significado peculiar que a palavra social tem para Tarde,

“posto que não define um domínio específico da realidade ou uma zona ontológica particular reservada aos humanos, mas designa toda e qualquer modalidade de associação; de forma que, em vez de substância, o social é sempre relação, logo, diferença" (Vargas 2007: 21).

Recentemente, também Bruno Latour (2007) tem se preocupado em defender essa perspectiva tardeana no tratamento do social. Como sugere esse autor, a idéia de sociedade ou, de maneira mais ampla, a idéia de social, está presente nas Ciências Sociais desde o seu surgimento, até mesmo como condição para o seu surgimento. Mas o que é o social?, pergunta-se Latour. Eis uma simples pergunta, cuja resposta não é fácil, pois é justamente à resposta fácil - aquela que damos prontamente - que Latour quer se contrapor, em favor de uma redefinição do que são laços sociais.

Segundo Latour (2007), o adjetivo "social" do "cientista social", ou de "ciência social", não é problemático se pensado nos termos originais de desígnio de estabelecimento de afetos, ou conjunto de laços, como propunha originalmente Gabriel Tarde. O problema, segundo o autor, é quando esse social torna-se algo material, como "biológico", "metálico" ou "econômico", como em boa parte das respostas que se dá a sua pergunta; o que ele deseja é mostrar como "o social" não é uma construção material de algum domínio, mas sim um estado de afetos. 
Para o autor, a primeira solução que se dá à questão do que é "social" remete a pensar em uma espécie de contexto - "contexto social", ou "dimensão social", ou "ordem social", ou "prática social", ou "estrutura social" - onde domínios da realidade, como a economia, a biologia, a geografia, o direito, a psicologia, para citar alguns, estão em parte situados. Neste caso, o social aparece de maneira negativa, como aquela instância que faz perder a pureza de algum desses domínios, cuja totalidade deve prever aquelas nuvens dos "aspectos sociais", ou dos "fatores sociais", que geralmente são tomados como o fator de desordem - aquilo de que não se pode ter o controle do rigor científico, justamente por não se saber ao certo as conseqüências daquelas dimensões obscuras e mutantes.

Neste breve ensaio teórico, procuro refletir sobre as possibilidades infinitas de construir-se na diferença, de possuir-se pelos outros, de possuí-los, de traduzir em si múltiplas possibilidades de gênero, de corporalidades, tão eventualmente se transformando quanto transformando outros, no processo, na expressão, nos possíveis mundos no ciberespaço, que podem incluir agências diversas e momentâneas como cores, emoticons, movimentos na tela, no teclado, na velocidade de digitação das frases, enfim, tudo aquilo que faz fazer e que pode ser vivido no [e pelo] ciberespaço. Para tanto, tomo como exemplo para discussão duas breves passagens de meu diário de campo sobre as salas de bate-papo Lésbicas e Afins do grupo Sexo, do portal UOL de internet, datadas ainda de janeiro de $2006^{2}$ e relidas à luz de meus atuais interesses em pesquisa e de leituras que venho fazendo contemporaneamente.

Nesse sentido, o intuito central deste ensaio é modesto: não cabe em minhas pretensões neófitas traçar uma análise aprofundada sobre gênero ou corporalidade, tampouco sobre as múltiplas possibilidades de se teorizar em antropologia o ciberespaço. Antes sim, de maneira intuitiva, pretendo aproximar as discussões que têm sido reacendidas com o resgate da obra de Gabriel Tarde nos últimos anos e alguns dados de campo que possam sugerir alguma relação entre variações de mundo onde cada um pode ser, ao mesmo tempo, "um meio universal ou que aspira sê-lo, um universo para si, não apenas um microcosmo [...], mas o cosmo inteiro conquistado e absorvido por um único ser" (Tarde 2007:80), tal qual não pode ser explicado ou interpretado; mas antes, e tão somente, multiplicado (Viveiros de Castro 2002) na imanência de seu mundo possível.

\section{O CIBERESPACO E AS LÉSBICAS E AFINS}

Há cerca de quinze anos, quando Nicholas Negroponte, preocupado com as representações gráficas de pessoas na interface - onde as pessoas e os bits se encontram -, perguntava-se "por que é tão difícil 'ser digital'" (Negroponte 1995:89), acredito que ele não esperasse que pudéssemos, realmente, "ser" no "mundo digital". Entretanto, cada vez mais presente no cotidiano, o ciberespaço vem dinamizando a maneira como as pessoas vêm se constituindo e constituindo as suas redes de relações. Construído e apropriado no cotidiano sob muitas formas e qualidades, ele oferece um sem-fim de espaços e meios para a interação, como telefones celulares, correios eletrônicos, MSN, orkut ou as clássicas salas de bate-papo, onde cada vez mais outros modos de ser vão sendo construídos ${ }^{3}$.

Para esta reflexão, escolhi as salas de bate-papo intituladas Lésbicas e Afins, do grupo Sexo, do portal UOL de internet, cuja heterogeneidade é marcada pela participação não somente de sujeitos que se apresentam como "lésbicas" ou "afins", como supõe a nomeação do espaço, mas pelo grande número de sujeitos que se 
apresentam como "homens", como "mulheres não-lésbicas", como "bi", e que de alguma forma "aceitam" a possível identificação "lésbica" que a sala sugere - ou mesmo impõe - ao escolherem justamente estas salas como espaço para interação, dentre tantas que o portal UOL oferece para os seus usuários. A bem da verdade, foi a partir dessa primeira e simples constatação que me iniciei na pesquisa naquilo que temos chamado de Antropologia do Ciberespaço ${ }^{4}$, então com o intuito de refletir sobre os modos de apresentação dos sujeitos - a escolha das cores de fonte, os apelidos, uso de emoticons e fotos para a representação visual de si no ambiente - e as possíveis contradições entre estes modos de apresentação e representação em relação às suas vivências no ambiente. Em suma, eu procurava refletir sobre a possibilidade de utilização do ciberespaço, neste caso especialmente as salas de bate-papo Lésbicas e Afins (LeA) do portal UOL, como ambientes/espaços (e meios) alternativos de vivências ${ }^{5}$ que possibilitam a construção de corporalidades, subjetividades e identidades de gênero que vão para além de um eu organizado, fixo e ontológico.

Um dos meus pontos teóricos de partida para meus trabalhos neste campo pode ser encontrado em parte da obra da antropóloga feminista Henrietta Moore (2000), que escreve que há discursos e práticas discursivas que fornecem posições de sujeito, o que logo sugere não haver um sujeito a ser posicionado, ou marcado; não há um sujeito homogêneo e totalizável por uma única subjetividade. Nas suas palavras:

“[...] os indivíduos assumem uma variedade de posições de sujeito dentro de diferentes discursos. Entre outras coisas, isso significa que um sujeito singular não pode ser equivalente a um indivíduo singular. Indivíduos são sujeitos multiplamente constituídos, e podem assim assumir múltiplas posições de sujeito dentro de uma gama de discursos e práticas sociais. Algumas dessas posições de sujeito serão contraditórias e entrarão em conflito entre si" (Moore 2000:23-24).

No caso das salas de bate-papo $L e A$ eu questionava se sua nomeação já não estaria de alguma forma construindo subjetividades nos sujeitos que aceitam esta "imposição" que o ingresso nas salas supõe (ser lésbica ou, ao menos, "afim"), além das cores das fontes, a escolha dos apelidos, enfim, tudo aquilo que poderia estar fazendo parte deste processo de construção de corporalidade, subjetividades, ou do gênero. A heterogeneidade começa no sujeito, nas suas muitas e múltiplas formas de ser, que poderiam estar emergindo neste processo que começaria, neste caso, desde a escolha do grupo Sexo, a escolha das salas $L e A$, a escolha do apelido, das cores de fonte ou dos emoticons e fotos que identificam os sujeitos nestas salas de bate-papo. Elementos que podem formar uma espécie de matriz - não referencial - sobre a qual, performativamente, se pode construir-se naquele espaço.

Seguindo esta pista, ao longo do texto procuro fazer algumas aproximações entre experiências de campo nestas salas e noções de performatividade e de multiplicidades de agências, especialmente aquelas construídas nas teorias feministas do sujeito e nos trabalhos de inspiração tardeana. 
"Apenas Olhando". Foi este um dos muitos apelidos que escolhi para entrar nas salas $L e A$ enquanto eu fazia campo para minhas pesquisas. A cor era cinza, de ar apagado e disfarçado. Dias antes eu havia entrado com a cor vermelha e alguém me dissera que eu estava "com fogo". Percebi então que a escolha do apelido era algo que poderia me exigir um pouco mais de reflexão. Resolvi me camuflar com "Apenas Olhando".

$\mathrm{Na}$ dita ocasião, eu não queria que meu apelido chamasse a atenção dos participantes do bate-papo e, a bem da verdade, fui bastante sincero - entrei para apenas olhar, não queria falar com ninguém, mas sim observar um pouco as conversas: como se apresentavam, o que diziam, o que perguntavam, o que respondiam - entre si, mas não comigo; minhas perguntas eram "muito acadêmicas". Eu ainda não falava o idioma daquela "tribo". Mas Geertz (2003) tinha razão ao alertar - em sua crítica ao mito do antropólogo camaleão que se camufla entre os nativos, sustentado classicamente na obra malinowskiana - que a idéia de "não chamar atenção" é insustentável, tanto que naquela ocasião fui interpelado com um "tá olhando pra mim?" e um outro "tá gostando do que vê?".

Eu havia procurado construir um "corpo feio", cinza, "sem graça", que eu achava não-interessante e, para desviar das perguntas, me apresentei para "Querida" e expliquei que o que me motivara a entrar era uma pesquisa acadêmica. Logo depois de aparentemente "conquistar sua confiança", perguntei-lhe sobre os motivos dos participantes insistirem tanto em sair da sala e continuar a relação no $M S N$, já que naquela altura eu já havia assistido a muitas dessas cenas, bem como tais convites já haviam sido a mim dirigidos. Ela me disse estar com pressa (eu, de fato, não parecia interessante de cinza), mas me explicou que a sala de bate-papo é como uma festa: você entra, vê várias pessoas desconhecidas dentro de um mesmo espaço, como numa "balada". Essas pessoas entreolham-se, avaliam a beleza, o jeito, o corpo (no caso, lêem os apelidos), tomam coragem, aproximam-se para conversar, ou flertar. Se o papo for bom, se a pessoa for interessante, "a gente chama pro canto e pega que nem na balada e se der, ainda leva pra cama", dizia-me ela.

Em certo sentido, parece-me que os apelidos falam sobre (e pelas) pessoas na sala, como uma espécie de corpo mesmo - daí a importância de perceber a grande utilização de apelidos como "peitudinha", "bundinha", "tesudinha_sp", "safadinha-msn", "loirinha-quer-sexo" ou, "molhadinha_cam", que muito mais do que falar sobre um corpo que se tem, dão a impressão de falar sobre um corpo que se deseja - são corpos sustentados pelo desejo e fantasias mútuas: a "peitudinha" pode construir, para ela, o corpo da "loirinha", enquanto a "loirinha" pode construir o corpo da "peitudinha" uma para a outra: o referente da "peitudinha" está na "loirinha" e viceversa. Em suma, o corpo que uma tem para si, pode não ser o mesmo que o outro tem. Um pacto de fantasias, ou invenções/convenções, nos dizeres de Wagner (1981), onde cada um traz consigo algum referente que faz inventar o outro reciprocamente no encontro ${ }^{6}$.

Já nas palavras de Campbell, os apelidos são a primeira impressão que se tem da pessoa quando se entra na sala, como na "balada". Segundo ele, "o apelido online [...] pode revelar-se um aspecto profundamente pessoal da identidade de um participante em um determinado canal e precisa ser tratado com o devido cuidado pelo pesquisador" (Campbell 2004:48). Em seu recente trabalho, o autor faz uma interessante etnografia em 
canais gays do $\mathrm{IRC}^{7}$, onde ele investiga a construção de identidades a partir das vivências nos canais. Para ele, a possibilidade de se construir (corpo, subjetividade, identidade) no ciberespaço é, para os participantes desses canais, a possibilidade de romper com as estruturas opressivas de identidades de gênero, marcadas por matrizes heterossexuais ocidentais:

“[...] o fato de que nestes espaços virtuais se testemunhe a exploração e expressão de modos alternativos de prática sexual ou novas configurações do corpo sexual [...] não sugere que estes indivíduos estejam emancipados das relações de poder dominantes ou que estes indivíduos não sejam igualmente capazes de reproduzir hierarquias repressivas. No entanto, há razões para argumentar que esses arranjos sexuais alternativos em torno do corpo indicam o caráter construído e a artificialidade dos entendimentos binários do sexo (masculino/feminino) e da sexualidade (heterossexual/homossexual), e, portanto, mantêm o potencial de desestabilizar essas 'verdades' fundamentais para as estruturas de poder dominantes" (Campbell 2004:149).

Campbell faz seu trabalho de campo em dois canais, "\#gaymusclebears" e "\#gaychub", mostrando como gays têm a oportunidade de falar sobre seus corpos e de sentir prazeres, desejos, enfim, de viver a sua sexualidade a partir da autoimagem do que eles são, ou que podem construir do seu corpo através da escrita e das interações e relações que eles estabelecem no canal. Tais imagens e, em casos, tais identidades, não são necessariamente aquelas vividas ou apresentadas em outros contextos, especialmente no mundo off-line. Mas, segundo o autor, essas interações online dependem, e muito, desse corpo, seja ele representado graficamente, seja ele descrito por meio de palavras ou apelidos, construído na sala de bate-papo: ele é "um componente primário da identidade on-line" (ibid.:6). Ainda segundo Campbell, estes corpos, principalmente os construídos nos apelidos dos participantes, são especialmente orientados pela exploração da erotização das imagens dos corpos off-line que, no caso de seu trabalho, referem-se aos corpos masculinos. Nas suas palavras, "o corpo continua presente no ciberespaço, porque aquilo a que nos referimos como o 'corpo' é simultaneamente uma forma física e a apreensão do físico por uma configuração discursiva, e é esta configuração discursiva que acompanha os indivíduos nesses ambientes virtuais e que conforma a interação online" (id.). Nesse caso, objetividade e subjetividade são elementos que carregam os apelidos: por um lado podem indicar os meus interesses na sala, por outro podem dar aspectos de meu corpo, meus traços físicos "reais" mas, especialmente, sugerem aqueles traços físicos que possibilitem que o outro me construa de forma a me desejar - aqueles que eu quero que o outro tenha para mim, de $\mathrm{mim}$. Os apelidos, pode-se dizer, são construídos em função da relação que espero do outro em relação a mim na sala, como eu quero que me vejam, como quero que me olhem entre tantas pessoas nesta festa - mesmo que não se tenha tal intenção, como no caso do antropólogo "Apenas Olhando" que, tomado por voyeur, com candidatos prontos à exibição, é chamado a ver o que quiser ver, do outro, em si. Neste sentido, o apelido parece uma matriz não referencial (que não organiza ontologicamente) de construção de corpos, identidades de gênero e subjetividades. E eu tava na festa.

Essas muitas subjetividades dos sujeitos são abordadas pelo sociólogo, estudioso da comunicação, Francis Jauréguiberry (2000), que escreve que muitos papéis que não podem ser vivenciados em outras esferas da vida social, são vivenciados nas salas de bate-papo. Segundo ele, há uma espécie de realização de desejos 
que em outros espaços não são permitidos "ao eu" e que ganhariam "vida" no ciberespaço. Para o autor francês, "nesta perspectiva a internet se investe como um espaço potencial que permite aos indivíduos a reconstrução da realidade através da experimentação de uma ilusão" (Jauréguiberry 2000:148). Esta reconstrução da realidade que possibilita a experimentação de um desejo, de uma pulsão, ou fantasia, Jauréguiberry chama de manipulação de si. Para o autor, "as 'manipulações de si' às quais certos internautas se entregam ao se servir de um sexo, uma idade, um estatuto etc. diferentes dos seus nos fóruns de discussão ou no IRC se multiplicam" (ibid.:150), o que poderia ser compreendido como processos de construção de subjetividades que possibilitariam outras vivências, por meio de outros "eus", em outros espaços, mas que não deixariam de ser parte de um sujeito múltiplo, como aponta Moore:

“A noção do sujeito como lugar de subjetividades múltiplas e potencialmente contraditórias é muito útil. Se a subjetividade for vista como singular, fixa e coerente, torna-se muito difícil explorar como os indivíduos constituem seu sentido de si mesmos - suas auto-representações como sujeitos - por referência a várias posições de sujeito freqüentemente contraditórias entre si e não a uma posição singular de sujeito (Moore 2000:23).

Apontando também para a possibilidade de construir-se multiplamente, entretanto apontando mais para o caminho de investigar as construções de identidades em ambientes de jogos on-line ${ }^{8}$, está o trabalho de Sherry Turkle (1995), para quem mesmo as fantasias, as brincadeiras, ou até aquilo que pode ser apontado pelos sujeitos como mentiras sobre si, negando tais vivências, na verdade podem estar construindo outros "eus", outras identidades que de alguma forma fazem parte de um eu que elas são. Segundo Turkle, "no anonimato dos MUDs - onde os sujeitos são personagens - dá para se expressar em várias pessoas e, muitas vezes, inexplorados aspectos do 'eu' para jogar com sua identidade e para testar novas. MUDs tornam possível a criação de uma identidade fluida" (Turkle 1995:12). A autora faz pensar na possibilidade de brincar com essas identidades fluidas e múltiplas.

Em outro trabalho, nessa mesma linha, ela também escreve:

“Cada vez mais, vivemos em um mundo no qual você acorda como amante, toma café da manhã como mãe e dirige o seu carro para o trabalho como advogada. Em um mesmo dia, as pessoas passam por transições drásticas, e é evidente que desempenham múltiplas funções. [...] Na internet, você se vê atuando em sete janelas abertas na tela, assumindo literalmente diferentes personalidades em cada uma dessas sete janelas, tendo todos os tipos de relacionamentos, alternando e desempenhando todas as funções simultaneamente, deixando partes de si nessas diferentes janelas, nos programas que escreveu e que o representam enquanto você está em outra janela. Sua identidade é distribuída em uma série de janelas. Cada vez mais, a vida na tela também oferece uma janela para o que somos na vida fora da tela: somos pessoas que alternamos aspectos do eu" (Turkle 1997:264).

Em contraste ainda a esta idéia de Turkle $(1995,1997)$ de um "eu" que pode ser multiplicado, Judith Bultler, filósofa feminista, ao falar das identidades de gênero performativamente construídas, aponta para a direção de que não haveria um "eu" ontologicamente construído que preceda esses outros "eus", já que, no caso do gênero, "não 
há identidade de gênero por trás das expressões de gênero; essa identidade é performativamente constituída, pelas próprias 'expressões' tidas como seus resultados" (Butler 2004:45). Para a autora, em certo sentido não haveria um sujeito ontologicamente constituído que é multiplicado, não haveria um "eu essencial" que antecede as relações, mesmo que em alguns momentos esses sujeitos, pela exclusão de outros sujeitos não-autorizados, providenciem um sujeito ideal, construído na interpelação de si, aproximando-se a categorias identitárias fixas que "tendem a ser instrumentos de regimes regulatórios, seja como categorias normalizadoras de estruturas de opressão ou como formas de mobilização para a contestação libertária dessa mesma opressão" (Butler 1991:1314). Esse sujeito idealizado, adequado a algum tipo de regime regulatório de identidade, fica muito próximo do que pode ser observado nos usos "dissimulados" de identidades como mulher, lésbica, bi, que tendem a promover uma adequação do(a) usuário(a) das salas a algum regime identitário, já que ele necessita escolher entre algumas categorias identitárias as quais ele supõe dever compartilhar para ser aceito no espaço. É o que Butler chama de "sujeito nominal", que faz uma totalização de um eu de forma mais ou menos situacional:

“Sustentar que sou isso é sugerir uma totalização provisional desse 'eu'. Mas se o 'eu' pode determinar-se, então aquilo que exclui para fazer essa determinação permanece constitutivo da própria determinação. Em outras palavras, tal afirmação pressupõe que o 'eu' exceda sua determinação, e mesmo produza esse excesso no e pelo ato que busca exaurir o campo semântico do 'eu'. No ato que manifestaria o conteúdo verdadeiro e completo daquele 'eu', certa dissimulação radical é produzida. Pois fica sempre obscuro o que se quer dizer ao invocar o significante lésbica, uma vez que sua significação está sempre até certo ponto fora de controle, mas também por que sua especificidade só pode ser demarcada por exclusões que voltam a romper com essa reivindicação de coerência" (Butler 1991:15 - grifos no original).

Essa totalização provisória de um "eu" cria, mais ou menos coerentemente, um "sujeito central" - ou como ela mesma sugere: um sujeito que se constitui mediante a exclusão de outros sujeitos, isto é, mediante a criação de um domínio de sujeitos desautorizados na diferenciação entre sujeito e abjeto - aquele que não tem lugar (Butler 1998). Para a autora, isso acontece na performatividade, na vivência. Neste caso, não há um sujeito central ali, acabado, pronto, que emerge quando chamado, mas sim esse sujeito é constituído, mais ou menos provisoriamente, no processo - para ela, não se está falando de um sujeito ontológico que é solicitado à cena, mas de um sujeito que emerge no processo de diferenciação entre outros sujeitos dentro de um campo de possibilidades temporal-contextual.

Falar em campo de possibilidades, logo explico, não quer dizer que há uma série de matrizes de sujeitos dados e que podem se escolhidos para serem criados - os sujeitos não-autorizados de Butler (1991, 1998), me parece, também são processuais, a exclusão de outros sujeitos também acontece no processo - há um movimento de dupla mão: exclusão construção. Neste sentido, para Butler (1991), responder, por exemplo, aos campos apelido, cor, criando uma espécie de perfil necessário ao ingresso nas salas, exige que se auto-determine os limites do campo semântico do "eu" - a própria palavra perfil, neste caso, aponta para este caminho; perfil diz respeito à descrição básica e concisa do contorno do corpo e, para Butler, o "eu" - e o corpo - mesmo que importando ${ }^{9}$, não é algo que possa ser pensado em termos ontológicos, que possua substância ou essência, mas processos performaticamente construídos em contextos diversos, que tendem a ser congelados quando se 
é interpelado sobre si na "porta de entrada da festa". Mas lá dentro, na relação, os referentes utilizados para se totalizar provisoriamente um "eu" para entrar são dissolvidos em função da construção performativa, processual do contexto. É preciso, para autora, que em certa medida se "invente" alguns "eus" provisórios, que logo se diluem no processo, na relação. E eles se diluem de relação em relação - a "loirinha" constrói a "safadinha" de uma maneira diferente de como se constrói para a "bundinha", que foi construída de maneira diferente pela "molhadinha_cam", ou pelo "Apenas Olhando".

Assim, para Butler (1991, 2004), não haveria um sujeito ontologicamente constituído que é multiplicado (Turkle 1995, 1997), não haveria um "eu" essencial ontologicamente constituído que preceda esses outros "eus" que são auto-representados (Moore 2000) ou apenas representados na vida cotidiana (Goffman 1975), pois eles não possuem referentes que os antecedam - e se os têm, são estratos, engastados em outros estratos de construções provisórias de "eus". Destarte, é interessante lembrar ainda que nestas investigações em antropologia do ciberespaço a noção de performance, classicamente utilizada em outros campos de investigação da antropologia, permite, segundo Guimarães Jr., "compreender as práticas de sociabilidade de uma cultura a partir de sua concretização em palavras, sons, movimentos, roupas ou gestos" (Guimarães Jr. 2000, s/p). Ela é apontada como uma noção privilegiada para se perceber como acontecem os processos de interação e construção de subjetividades também no ciberespaço, justamente por ter esse caráter de "uma experiência humana contextualizada, e [porque] a análise performática explora a dinâmica da expressão poética do evento e não a fixação do evento como um texto de narrativa ou um manuscrito de uma peça de teatro" (Langdon 1996:26). Logo, como continua Langdon (1996), "entram em cena os interesses sobre a força da experiência, a subjetividade" (id.), vistos "como o fluxo da vida cotidiana" (id.). Analisar a vida social sob esta ótica implica contestar aquela visão de cultura como um modelo ideal, fixo e abstrato em favor de uma visão de cultura "como emergente, estando o seu enfoque no ator social como agente consciente, interpretativo e subjetivo" (ibid.:24).

No caso ainda do ciberespaço, Rifiotis (2002) chama atenção para o fato de a performance ajudar a compreender que "o fluxo verbal escrito, apesar de importante, não é o único, e é muitas vezes de modo combinado com o som, imagem e desde muito cedo com as maiúsculas e com os emoticons, levando a pensar numa oralidade escrita" (Rifiotis 2002:8 - comentando o trabalho de Guimarães Jr., em nota de rodapé), o que implica dizer que a noção de performance torna-se útil para a análise daquilo que vai além das palavras escritas naquele espaço e que, de alguma forma, faz parte desse processo de construção de subjetividades numa interação que pode indicar emoção, pertença, confiança, afetividade ${ }^{10}$. 


\title{
DE TARDE A DELEUZE: NA PERSPECTIVA DO CORPO SEM GÊNERO (CSG)
}

\author{
Ao Corpo sem Órgãos não se chega, \\ não se pode chegar, \\ nunca se acaba de chegar a ele, \\ é um limite. \\ Deleuze \& Guattari
}

O "corpo sem órgãos" de Deleuze e Guattari (2004) não nos diz muito sobre o que é um corpo, justamente por estar além daquilo que se pode esperar em conceitos e noções: ele é um conjunto de práticas que não se define em materialidade, em ontologia, tampouco em formas, cheiros, traços certos ou incertos: ele é uma nebulosa do sentir, do querer, do desejar - talvez uma pulsão, sem forma, nem referente, que se improvisa de vez em vez, em algum estrato que ousa se sedimentar para o bem convir político e contextual.

Não seria por menos que Deleuze e Guattari abrem o texto com a figura mítica do ovo Dogon que carrega em si todas as intensidades imanentes em um único espaço para se explodir em toda a vida Dogon ${ }^{11}$. 0 corpo sem órgãos vai além da forma, do molde - vai além do organismo - do corpo com órgãos, organizado. $O$ organismo é sujeito com significado, sujeito interpretado, sujeito material. O corpo sem órgãos é a experiência, sem interpretação - a interpretação já congela, já organiza. Ele é o sujeito que se lança de estrato em estrato sem nunca se chegar completo - é devir -, para além dos seus fantasmas, dos conjuntos de significâncias e subjetivações - é o que sobra inquieto, fazendo-se.

Certamente é difícil pensar em sujeitos quando se olha para a interface de um computador e se observa uma série de códigos, caracteres, desenhos ou fotos. Certamente é difícil pensar em corpo quando se fala em apelidos em uma sala de bate-papo. Mas não é difícil senti-los, e não é difícil porque não se escreve recados para caracteres, não se flerta com fotos, não se combina festas com códigos - faz-se isso com pessoas, sente-se pessoas. Sente-se de maneira não organizada - o organismo organiza, o que se sente não precisa de organização. A inspiração deleuziana é desorganizadora, nos coloca em diálogo com outras perspectivas de mundo - nos incita, nos dizeres de Viveiros de Castro (2002), a relacionar variações.

Destarte, pode-se ganhar muito mais em termos analíticos se abdicarmos de pensar que o que compõe a "vida social" são elementos mais ou menos homogêneos - a dizer, grosso modo, sujeitos humanos -; mas, ao contrário, pensarmos, como na sugestão de Latour (2007) ao tratar do trabalho de Gabriel Tarde, associações entre elementos heterogêneos. Isso consiste em sugerir que não há como continuar pensando nas coisas em si mesmas, ou que elas existem em si mesmas e que as conhecemos por que estamos distantes delas; se podemos conhecê-las e dizer algo sobre elas, é porque estamos mais próximos delas do que imaginamos. Nas palavras de Vargas:

“A questão é que em Tarde a palavra social tem um significado muito peculiar, posto que não define um domínio específico da realidade ou uma zona ontológica particular reservada aos humanos, mas designa toda e qualquer modalidade de associação; de forma que, em vez de substância, social é sempre relação, logo, diferença (Vargas 2007:21). 
Dessa forma, como também tem proposto Latour (2007), é preciso pensar os não-humanos como atores também nesses coletivos de associações, afinal, "há sujeitos por toda a parte" (ibid.:23). Assim, fazer antropologia no ciberespaço, como no caso das salas LeA, significa não apenas se preocupar com a vivência dos humanos naquele espaço, mas pensar muito mais amplamente em quem, ou o que, também são atores naquelas vivências. É se abrir para pensar que o computador, a tela, as teclas, os sites, e tudo aquilo que não é humano, mas que me transforma, que me associa, que faz parte da relação, também são sujeitos nessas associações e justamente por se estar falando em redes sociotécnicas, se está falando em algo que não é apenas técnica, nem apenas social, mas que são sujeitos híbridos que se estendem coletando humanos e não-humanos, transformando-os e por eles sendo transformados, em constante movimento, rompendo com corporalidades e com gêneros, como tradicionalmente o são tomados ${ }^{12}$.

E eu me perguntava: "Bundinhas", "Peitinhos", Molhadinhas", não são significantes e ontológicos? Como construções de subjetividades, elas continuariam, ao menos por algum período de tempo, a constituir aqueles sujeitos que participam das salas de bate-papo, ou tão logo desconectadas do ciberespaço, elas desapareceriam? Acredito que não. Elas ainda se mantêm, da mesma forma que há significância nos apelidos. Mas não são significantes absolutos.

“É necessário guardar o suficiente do organismo para que ele se recomponha a cada aurora; pequenas provisões de significância e de interpretação, é também necessário conservar, inclusive para opô-las a seu próprio sistema, quando as circunstâncias o exigem, quando as coisas, as pessoas, inclusive as situações nos obrigam; e pequenas rações de subjetividade, é preciso conservar suficientemente para poder responder à realidade dominante. Imitem os estratos. Não se chega ao CsO e seu plano de consistência desestratificando grosseiramente" (Deleuze \& Guattari 2004:23).

Como o corpo sem órgãos, os apelidos não são colados permanentemente a seus referentes e seus referentes não são fixos e únicos. As referências podem ser as mais diversas, com os mais diversos significados e, a exemplo do $\mathrm{CsO}$, são limites também - nunca se termina de chegar a eles.

Da mesma forma, como matrizes, esses apelidos não precisam necessariamente ser gendrados. Se você constrói um corpo (e/ou corporifica ${ }^{13}$ um apelido) e subjetividades, pode-se construir identidades de gênero também na performatividade. Nietzsche, citado por Butler, sugere que "não há 'ser' por trás do fazer, do realizar e do tornar-se; o 'fazedor' é uma mera ficção acrescentada à obra - a obra é tudo" (Nietzsche apud Butler 2003:48). Da mesma forma, escreve Maffesoli (2001) em Sobre o Nomadismo, o sujeito "não existe a não ser na relação (nas relações)" (Maffesoli 2001:30). As vivências nas salas, mesmo gendradas, não advêm necessariamente de identidades de gênero pré-definidas, tampouco de corpos gendrados - há os apelidos, deles se constroem vivências. E se essas matrizes não precisam ser gendradas, pode-se pensar em construir um Corpo sem Gênero (CsG).

Um CsG é um misto de intensidades que não precisam estar coladas a um referente gendrado, é o fazer, a obra indiferente ao fazedor. Um CsG é polimorfo ${ }^{14}$. Acima de tudo, pensar em um CsG é pensar em romper com as idéias hetero-fixas, hetero-organizadas e hetero-significadas de corpo, para pensá-lo performativamente, processual, infinito na sua variação. Assim, como sugere Viveiros de Castro (2002:122), se o objeto da antropologia 
seria a variação das relações sociais - não tomadas como ontologicamente distintas, mas de todos os fenômenos possíveis compreendidos como relações sociais, ou de todas as relações como sociais, parece interessante se abrir a uma perspectiva pronta a admitir que a compreensão de todas as relações como sociais pode implicar mesmo reconceitualizar radicalmente o que se compreende por social, neste caso, admitir um mundo possível onde bits e bytes, alguns códigos binários, caracteres dispostos na tela de uma máquina e coisas assim fazem parte daquilo do social de pessoas que inclusive as podem ser.

Enfim, não é caso de pôr em discussão a verdade sobre corpos sem gênero, identidades polimorfas e eventuais. Verdadeiramente, elas existem, entretanto talvez não nos limites conceituais de nossos mundos possíveis. E isso não nos impede de refletir sobre os mundos possíveis que aqueles outros conceitos projetam, não buscando interpretações daqueles pensamentos, mas buscando uma experimentação com eles, reciprocamente com o nosso ${ }^{15}$, em uma antropologia que pense em formas diversas de ser, com mundos, sujeitos e subjetividades no plural, efêmeros ou duradouros; gendrados ou polimorfos; mundos e sujeitos que são relação e diferença, e não mundos ou sujeitos que previamente são, para depois fazerem relações. Enfim, uma antropologia que encontra na emergência dessa construção e apropriação do ciberespaço um lugar privilegiado para refletir sobre vivências e multiplicidades de variações dessa pluralidade de mundos e sujeitos os mais diversos que, como nos dizeres de De Certeau (2002), inventam-se de mil maneiras em suas constantes traduções. 
1 Este artigo compreende parte de um trabalho maior de pesquisa que iniciei ainda no mestrado em Antropologia Social no PPGAS/UFSC, em 2005. Nele tenho me proposto investigar as dimensões vivenciais de sujeitos no/pelo ciberespaço. Agradeço ao CNPq pelo financiamento à pesquisa no mestrado; à UNIDAVI (Universidade para o Desenvolvimento do Alto Vale do Itajaí) pela concessão de auxílio para qualificação de docentes no doutorado. Agradeço especialmente ao professor Theophilos Rifiotis, que orienta meus trabalhos, e às professoras Sônia Weidner Maluf e Miriam Pillar Grossi, pelas ricas interlocuções nas disciplinas por elas oferecidas no PPGAS/UFSC, a que assisti entre 2005 e 2007. Por fim, meu agradecimento à Comissão Editorial desta revista, pelas valorosas sugestões a este trabalho.

2 Na ocasião, mesmo iniciado o trabalho de campo, suspendi temporariamente a pesquisa neste espaço, migrando no mesmo mês para o orkut, em função de mudanças de interesse em meu trabalho. De todo modo, acredito que um "dialógo mudo e extemporâneo" entre as notas de campo de um aprendiz e os comentários de quem (ainda aprendiz) já está em outra etapa de pesquisa possa ser frutificante, como já sugeria Cardoso de Oliveira (2002).

3 Bits é o nome genérico das unidades de armazenamento de dados digitais. Bits compõem os Bytes, que compõem os Megabytes, que compõem os Gigabytes, multiplicados em escalas de oito vezes. MSN é a sigla (e o nome adotado comumente) de um serviço disponibilizado pela Microsoft (Microsoft Network), chamado MSN Messenger que, associado a um endereço de e-mail, permite a interação em tempo real, por meio de escrita, voz e imagem. Já orkut é o nome de um espaço criado em uma plataforma beta que possibilita as mais diversas formas de interação em um ambiente genericamente chamado de "site de relacionamento". Para uma distinção entre plataformas e ambientes, consultar Guimarães Jr. (2000, 2004), e para maiores informações sobre o orkut, consultar Segata (2008).

4 Este trabalho tem sido desenvolvido no GrupCiber (Grupo de Pesquisas em Ciberantropologia) do PPGAS/UFSC. O GrupCiber é um grupo pioneiro no Brasil em pesquisas antropológicas no ciberespaço; com seus mais de dez anos de fundação, sob a coordenação do professor Theophilos Rifiotis, o grupo conta com três dissertações e uma tese defendidas e outra em andamento, todas tratando de aspectos da vida social no, pelo e com o ciberespaço.

5 Sobre o ciberespaço como "lugar alternativo" para vivências homossexuais, conferir os trabalhos de Nussbaumer (2001, 2005).

6 É interessante que se saiba que colhi apenas alguns dos apelidos que comumente aparecem nas salas e que aparentemente sugerem um apelo mais sexual. Entretanto, ao se olhar de maneira mais subjetiva, apelidos como "noite estrelada", "sonho" e "lua" podem ser tão sexuais quanto "molhadinha". De outro modo, cabe lembrar que a performatividade aqui proposta não sugere enclausurar uma ação nos contornos de um apelido, tampouco se propõe a ser um modelo explicativo. Há ainda também outros apelidos, ditos "mais comuns", como "bruna", "vida", "A", para citar alguns.

7 Sigla de Internet Reload Chat (Retransmissão de Bate-Papo pela Internet), que funciona de maneira similar aos chats, porém em outras plataformas que não a HTML. São redes formadas por diversos servidores onde as pessoas podem conversar; em cada rede existem canais, que são salas separadas por assunto.

8 Turkle (1995) analisa neste trabalho os MUDs (sigla que remete a Multi-User-Dungeon), jogos on-line da modalidade progressiva (isto é, que parecem não ter um fim a se chegar) jogados por muitos ao mesmo tempo. 
9 Butler (2005) não nega a materialidade do corpo - os corpos importam - entretanto, não são definitivos, tampouco referenciais.

10 Leia-se esta sugestão a título especulativo, uma vez que me faço ciente dos limites teóricos que se impõem entre a noção de performatividade presente especialmente nos trabalhos de Judith Butler e a Antropologia da Performance.

11 Uma referência-chave sobre esse grupo pode ser encontrada em Griaule (1975).

12 Dessa forma, ainda nos termos de Latour (2007), pode-se tomar o ciberespaço como um mediador: o zanzar pelos sites, as cores, os sons, os movimentos, são sujeitos, me transformam. Bits, bytes, pixels, e tudo o mais que me afeta naquele espaço, humanos, ou não-humanos, são sujeitos. As associações borram a separação entre minha pele e a tela de meu computador; eu me associo à máquina, ao computador e eu já não sou apenas humano, tampouco ele é apenas máquina. Formamos um coletivo.

13 Cf. Csordas (1994 e 2002) e Kepner (1987).

14 Cf. Rubin (1975).

15 Cf. Viveiros de Castro (2002), Wagner (1981) e Goldman (2006). 


\section{REFERÊNCIAS BIBLIOGRÁFICAS}

BUTLER, Judith. 1991. "Imitation and Gender Insubordination". In Diana Fuss (ed.) Inside/Out: lesbian theories, gay theories. New York \& London: Routledge, pp. 13-31.

42. . 1998. “Fundamentos Contingentes: o feminismo e a questão do 'pós-modernismo'” Cadernos Pagu 11:11. 2003. Problemas de Gênero: feminismo e subversão da identidade. Rio de Janeiro: Civilização Brasileira. .2005. Cuerpos que Importan: sobre los límites materiales y discursivos del "sexo". Buenos Aires: Paidós.

CAMPBELL, John Edward. 2004. Getting it on Online: cyberspace, gay male sexuality and embodied identity. New York: Harrington Park Press.

CARDOSO DE OLIVEIRA, Roberto. 2002. Os Diários e Suas Margens: viagem aos territórios Terêna e Tükúna. Brasília: UnB.

CSORDAS, T. 1994. Embodiment and Experience: the existencial ground of culture and self. Cambridge: Cambridge University Press.

.2002. "Shades of Representation and Being in Virtual Reality". In Body, Meaning, Healing: contemporary anthropology of religion. California: Palgrave, pp. 260-284.

DE CERTEAU, Michel. 2003. A Invenção do Cotidiano: 1. Artes de Fazer. 9. ed. Petrópolis: Vozes.

DELEUZE, Gilles; Félix GUATTARI. 2004. "28 de Novembro de 1947 - Como Criar para Si um Corpo sem Órgãos”. In Mil Platôs: capitalismo e esquizofrenia - Vol. 3. Rio de Janeiro: Editora 34, pp. 9-29.

GOFFMAN, Erving. 1985. A Representação do Eu na Vida Cotidiana. 3.ed. Petrópolis: Vozes.

GRIAULE, Marcel. 1975. Dieu D'Eau: entretiens avec Ogotemmêli. Paris: Fayard.

GUIMARÃES, Jr., M. J. L. 2000. Vivendo no Palace: etnografia de um ambiente de sociabilidade no ciberespaço. Dissertação de Mestrado em Antropologia Social. Florianópolis: Universidade Federal de Santa Catarina.

. 2004. "De Pés Descalços no Ciberespaço: tecnologia e cultura no cotidiano de um grupo social on-line". Horizontes Antropológicos 21: 123-154. Porto Alegre: UFRGS. 
JAURÉGUIBERRY, Francis. 2000. “Le Moi, Le Soi et Internet”. Sociologie et Sociétés 32(2):136-152.

KEPNER, James. 1987. Body Process: a gestalt approach to working with the body in psychotherapy. New York: Gestalt Institute of Cleveland Press.

LANGDON, Esther Jean. 1996. "Performance e Preocupações Pós-Modernas em Antropologia". In J. G. Teixeira (org.). Performáticos, Performance e Sociedade. Brasília: UnB, pp. 23-29.

LATOUR, Bruno. 2007. Reassembling the Social: an introduction to Actor-Network-Theory. Oxford: Oxford University Press.

MAFFESOLI, Michel. 2001. Sobre o Nomadismo: vagabundagens pós-modernas. Porto Alegre: Sulina.

MOORE, Henrietta. 2000. "Fantasias de Poder e Fantasias de Identidade: gênero, raça e violência". Cadernos Pagu 14:13-44.

NEGROPONTE, Nicholas. 1995. A Vida Digital. São Paulo: Companhia das Letras.

NUSSBAUMER, Gisele M. 2001. "Fora do Armário: a cibersocialidade em uma lista de discussão GLS". In A. Lemos e M. Palácios (orgs.). Janelas do Ciberespaço: comunicação e cibercultura. Porto Alegre: Sulina.

. 2005. "Sociabilidade e Escrita de Si em Comunidades Virtuais Gays". Texto apresentado no XIV Encontro Anual da Compós (Associação Nacional dos Programas de Pós-Graduação em Comunicação), GT "Comunicação e Sociabilidade". Niterói: Universidade Federal Fluminense, 03/06/2005 (recebido da autora por e-mail em 22/09/2005 - formato Word, pp. 01-09).

RIFIOTIS, Theophilos. 2002. "Antropologia do Ciberespaço: questões teórico-metodológicas sobre a pesquisa de campo e modelos de sociabilidade". Antropologia em Primeira Mão 51. Florianópolis: Programa de PósGraduação em Antropologia Social/Universidade Federal de Santa Catarina.

RUBIN, Gayle. 1975. "The Traffic in Women: notes on the 'Political Economy' of Sex". In Rayna Reiter (ed.) Toward an Anthropology of Women. New York: Monthly Rewiew Press, pp. 157-210.

SEGATA, Jean. 2008. Lontras e a Construção de Laços no Orkut: uma antropologia no ciberespaço. Rio do Sul: Nova Era.

TARDE, Gabriel. 2007. "Monadologia e Sociologia”. In . Monadologia e Sociologia - e outros ensaios. São

Paulo: Cosac \& Naify, pp. 51-133. 
TURKLE, Sherry. 1995. Life on the Screen: identity in the age of the internet. New York: Simon \& Schuster. . 1997. “Depoimento a John Brockman”. In J. Brockman, Digerati: encontros com a elite digital. Rio de Janeiro: Campos, pp. 259-268.

VARGAS, Eduardo Viana. 1995. "A Microssociologia de Gabriel Tarde". Revista Brasileira de Ciências Sociais 27:93-109.

2000. Antes Tarde do que Nunca: Gabriel Tarde e a emergência das ciências sociais. Rio de Janeiro: Contracapa.

. 2007. “Gabriel Tarde e a Diferença Infinitesimal”. In G. Tarde, Monadologia e Sociologia - e outros ensaios. São Paulo: Cosac \& Naify, pp. 7-49.

VIVEIROS DE CASTRO, Eduardo. 2002. “O Nativo Relativo”. Mana 8(1):113-148.

WAGNER, Roy. 1981. The Invention of Culture. 2.ed. Chicago: University of Chicago Press. 
Da Arte de se Traduzir: corporalidades e gênero nos mundos possíveis no ciberespaço

\section{RESUMO}

Neste ensaio teórico, de inspiração etnográfica, procuro explorar as possibilidades de variações de construir a si no ciberespaço, como construir para si e para outrem corpos sem gênero e identidades polimorfas, tomando como espaço de investigação as salas de bate-papo "Lésbicas e Afins", do grupo Sexo do portal UOL de internet. Minha reflexão reside especialmente na maneira como os sujeitos naqueles espaços se constroem nos/pelos apelidos. De modo mais amplo, o trabalho pretende refletir sobre a utilização do ciberespaço como meio e espaço para relações de gênero das mais diversas ordens: sentidas, vividas e experienciadas, talvez mais livremente, democraticamente e igualitariamente.

PALAVRAS-CHAVE: ciberespaço, performatividade, gênero, corporalidades.

The Art of Self-Translation: corporalities and gender in the possible cyberspace worlds

\section{ABSTRACT}

In this theoretical essay, ethnographically inspired, I seek to explore the variations of self-construction possibilities in the cyberspace, such as building ungendered bodies and polymorphic identities to oneself or to others. I take as locus of investigation the chat rooms "Lésbicas e Afins" of the group "Sex" of UOL internet portal. My attention is especially focused on the ways how subjects build themselves in those environments by the use of nicknames. More generally, my intention is to think about the use of cyberspace as means and space to a wide variety of gender relations which maybe are felt and experienced in more democratically and igualitarian ways.

KEYWORDS: cyberspace, performativity, gender, corporalities.

Recebido em 24/02/2008

Aprovado em 09/07/2008 